\title{
Comparison of an In-House Quantitative Real-Time PCR and COBAS AmpliPrep/TaqMan Roche for Determination of Viral Load for HIV Type 1 Non-B
}

\author{
Erick Ntambwe Kamangu1 ${ }^{*}$, Adawaye Chatte ${ }^{2}$, Raphael Boreux ${ }^{3}$, Fabrice Susin ${ }^{4}$, \\ Richard Lunganza Kalala', Georges Lelo Mvumbi' ${ }^{1}$, Patrick De $\mathrm{Mol}^{3}$, \\ Marie-Pierre Hayette ${ }^{3,4}$, Dolores Vaira ${ }^{4}$ \\ ${ }^{1}$ Unit of Molecular Biology, Department of Basic Sciences, Faculty of Medicine, University of Kinshasa (UNIKIN), \\ Kinshasa, Democratic Republic of Congo (DRC) \\ ${ }^{2}$ University Institute of Science and Technology of Abeche, Abeche, Chad \\ ${ }^{3}$ Laboratory of Clinical Microbiology, University Hospital-University of Liège, Liege, Belgium \\ ${ }^{4}$ AIDS Reference Laboratory (LRS), University Hospital-University of Liège, Liege, Belgium \\ Email: ${ }^{*}$ erick.kamangu@unikin.ac.cd
}

Received 1 March 2015; accepted 16 March 2015; published 20 March 2015

Copyright (C) 2015 by authors and OALib.

This work is licensed under the Creative Commons Attribution International License (CC BY).

http://creativecommons.org/licenses/by/4.0/

(c) (i) Open Access

\begin{abstract}
Context: The in-house techniques or experimental methods are increasingly recommended for their low-cost reagents for the determination of the Viral Load (VL) in resource-limited settings. The objective of this study was to compare the determination of VL from HIV-1 non-B samples by an in-house technique with the COBAS AmpliPrep/TaqMan version 2.0. Method: In this cross-sectional study, 39 plasma samples from patients infected with HIV type 1 non-B from N'Djamena and Kinshasa were used to determine the VL using the two techniques. Results: The mean values of VL are respectively $4.68 \pm 1.26$ and $4.58 \pm 1.33 \log _{10} \mathrm{RNA}$ copies/ml for the COBAS AmpliPrep/TaqMan assays and the in-house assays. A good correlation (Spearman Correlation) was obtained, with a coefficient $\left(R^{2}\right)$ of 0.9452 . Conclusion: This study demonstrates that there is no significant difference between the results of VL determined by the COBAS AmpliPrep/TaqMan assays and the in-house assays used.
\end{abstract}

\section{Keywords}

\section{COBAS AmpliPrep/TaqMan, In-House PCR Assays, HIV-1 Non-B}

\footnotetext{
"Corresponding author.
}

How to cite this paper: Kamangu, E.N., Chatte, A., Boreux, R., Susin, F., Kalala, R.L., Mvumbi, G.L., De Mol, P., Hayette, M.-P. and Vaira, D. (2015) Comparison of an In-House Quantitative Real-Time PCR and COBAS AmpliPrep/TaqMan Roche for Determination of Viral Load for HIV Type 1 Non-B. Open Access Library Journal, 2: e1402.

http://dx.doi.org/10.4236/oalib.1101402 


\section{Introduction}

The Antiretroviral Treatment (ART) seeks suppression of viremia in patients infected with Human Immunodeficiency Virus (HIV) [1]-[4]. The effect of ART suppressing HIV replication is measured by the monitoring of plasma Viral Load (VL), specially looking at treatment adherence or failure. Thus we speak of therapeutic success when the VL is undetectable or below the limit of detection ( $<20-100$ copies/ml) [1]-[4]. In its guide to the treatment of People Living with HIV (PLHIV) published in 2010, the World Health Organization (WHO) recommends measuring the VL as a key marker in monitoring of patients [4].

Several techniques are commercially available for the determination of VL using the principles of amplification and quantification of a specific region of Ribonucleic Acid (RNA) and complementary Deoxyribonucleic Acid (cDNA) [4] [5]. In addition, several other experimental techniques, called "in-house", have been developed to overcome the cost problems associated with techniques that are not marketed for use by low-income countries [4]-[8]. Several studies have compared different commercial and in-house assays, and non-significant differences have been related to the genetic diversity of HIV type 1 [6]-[9].

In-house assays are developed, and they can be improved according to the resources available in the laboratories. But it is of good practice that these assays should be validated with a panel of different subtypes of HIV-1. The objective of this study was to compare the results of VL samples of HIV-1 non-B obtained with an in-house assay and the COBAS AmpliPrep/TaqMan version 2.0 system.

\section{Methodology}

\subsection{Samples}

In this cross-sectional study, 39 plasma samples from patients infected with HIV type 1 non-B from N'Djamena (5 samples) and Kinshasa (34 samples) were included. All sera were chosen randomly from the panel of samples available. They were previously diagnosed for HIV-1 in the respective centers of origin by Rapid Diagnostic Tests. The aim of this study was to determine Viral Loads (VL) using the COBAS AmpliPrep/TaqMan HIV-1 (version 2.0) and compare the results with those given by an in-house Quantitative Real-Time PCR previously described in the literature [7] [8].

All manipulations were carried out in the AIDS Reference Laboratory of the University Hospital of Liège (LRS CHU-ULg). The VLs were run in duplicate and only the mean values were used for statistics.

\subsection{COBAS AmpliPrep/TaqIMan}

The COBAS AmpliPrep/TaqMan system 2.0 is a closed automated system that extracts the RNA from a volume of $1.0 \mathrm{ml}$ and amplifies it by targeting simultaneously a portion of the gag region and the Long Terminal Repeat (LTR) of the virus. The samples with less than $1.0 \mathrm{ml}$ of plasma were diluted by half and one tenth of the original volume in the sample obtained, using negative plasma to bring the total volume to $1.0 \mathrm{ml}$ tube. The dilution factor was taken into account for the interpretation of the results.

Once the sample is introduced into the automated system, the process of extraction, amplification and detection of the nucleic acids takes place automatically in a closed system. The COBAS AmpliPrep/TaqMan is based on 3 principles: 1) sample preparation for extraction of the RNA of the HIV Type 1, 2) execution of a Reverse Transcriptase PCR (RT-PCR) to generate a complementary Deoxyribose Nucleic Acid (cDNA), and 3) amplification of the cDNA with specific oligonucleotides.

\subsection{In-House Quantitative Real-Time PCR}

The RNA extraction was performed on $140 \mu \mathrm{l}$ of plasma using the QIAamp RNA Mini Kit QIAGEN ${ }^{\circledR}$ kit for RNA extraction with a final elution volume of $60 \mu$ [10]. After extraction, a Real-Time Quantitative PCR (qPCR) was performed according to protocols previously described [7] [8]. This qPCR has a Reverse Transcriptase PCR (RT-PCR) followed by quantification. The primers used were as followed: HIV1MGForward 
(5'-GCCTCAATAAAGCTTGCCTTGA-3'), HIV1MGReverse (5'-GGCGCCACTGCTAGAGATTTT-3') and the TaqManprobe was HIV1MGProbe FAM with Black Hole Quencher (5'-AAGTAGTGTGTGCCCGTCTGT TRTKTGACT-3'BHQ1) with the enzyme TaqMan One-Step. The region targeted by the PCR is part of the LTR which is the region described more or less protected from the genome of HIV type 1 [7] [9]. The calibration curve was plotted with commercial plasma controls previously quantified from $10^{2}$ to $10^{7}$ copies of viral RNA by an increment of a logarithm of 10 (\#94-2013 AcroMetrix Control Panel). The qPCR were performed on ABI $^{\circledR} 7500$ Fast Real-Time PCR System from Applied Biosystems (ABS).

\subsection{Sequencing and Subtyping}

The sequences of the Protease and Reverse Transcriptase (RT) were obtained using an "in-house" assay previously described by Steegen [11]. This technic was previously applied to determine the various strains of HIV-1 circulating in N'Djamena [12] and Kinshasa [13]. The pairing of sense and antisense sequences was performed with the software Vector NTI Advance ${ }^{\circledR} 11.5$ (Invitrogen, Life Technologies) and compared with the database of Stanford University (hivdb.stanford.edu) for the identification of sub-types HIV-1 [14].

\subsection{Statistics}

The statistical test Chi-square was used for qualitative variables and Student's t test for quantitative variables. The level of significance (p) was used for the probability of $\mathrm{p}<0.05$ (95\% CI). Any difference of more than 0.5 $\log _{10}$ is considered significant for the comparison of values of VL [15].

\section{Results}

Thirty nine (39) plasma samples were analyzed simultaneously for determination of Viral Load (VL) by the COBAS AmpliPrep/TaqMan and "in-house" assays.

The average values of VL are respectively $4.68 \pm 1.26$ and $4.58 \pm 1.33 \log _{10}$ copies $/ \mathrm{ml}$ for the COBAS AmpliPrep/TaqMan technology and the in-house (Table 1). The difference of the results from the two techniques are not significant, the VL found using both techniques are very similar $(\mathrm{p}<0.001)$.

The margin of $0.5 \log _{10}$ was used to assess differences between the results of two techniques. The dispersion of values is constant for both techniques; it varies from -1.13 to $0.57 \log _{10}$ RNA copies/ml (Figure 1 ). The negative values indicate a higher value of the COBAS while the positive values indicate a higher value of the in-house assay for the VL. For 4 samples (10.25\%), the difference between the 2 techniques is significant; it is greater than $0.50 \log _{10}$. But only 1 sample (2.56\%) had a value greater than the margin of $1.00 \log _{10}$. The correlation (Spearman Correlation) found is high, with a coefficient (R2) of 0.9452 (Figure 2).

The subtypes found in the samples are respectively: A (23.1\%), G (17.9\%), CRF02_AG (17.9\%), C (7.7\%), D (7.7\%), H (7.7\%), K (7.7\%), F (5.1\%), CRF01_AE (2.6\%) and J (2.6\%) (Figure 3).

\section{Discussion}

In this study, the performance of the COBAS AmpliPrep/TaqMan for determining the Viral Load (VL) of HIV type 1 was compared with that of an in-house Quantitative Real-Time PCR for non-B variants. Several alternative methods have been evaluated in recent years in order to make the VL determination available in countries with limited resources [5]-[9]. Concordant and comparable results have been published by various teams on various other techniques available for determining the VL for HIV-1 subtype B [5]-[9].

Table 1. Values of viral load ( $\log _{10}$ copies $\left./ \mathrm{ml}\right)$.

\begin{tabular}{ccc}
\hline Values & COBAS AmpliPrep/TaqMan & In-House Real-Time PCR \\
\hline Maximum Values & 7.70 & 7.68 \\
Minimum Values & 2.38 & 1.95 \\
Means & 4.68 & 4.58 \\
Standard Deviation & 1.26 & 1.33 \\
\hline
\end{tabular}




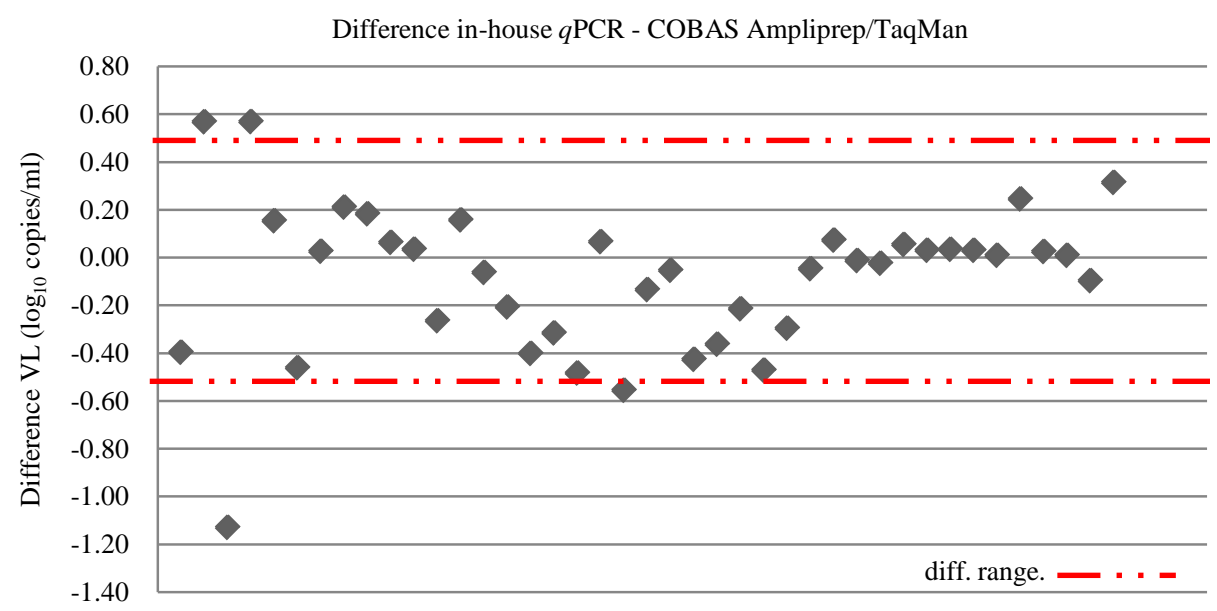

Figure 1. Degree of agreement between the COBAS AmpliPrep/TaqMan assays and in-house assays $\left(\log _{10}\right.$ copies $\left./ \mathrm{ml}\right)$. The results correspond to the difference in the values obtained by the in-house assay minus the COBAS AmpliPrep/TaqMan system. diff. range = difference range acceptable \pm 0.50 . Values within range are of $89.74 \%$.

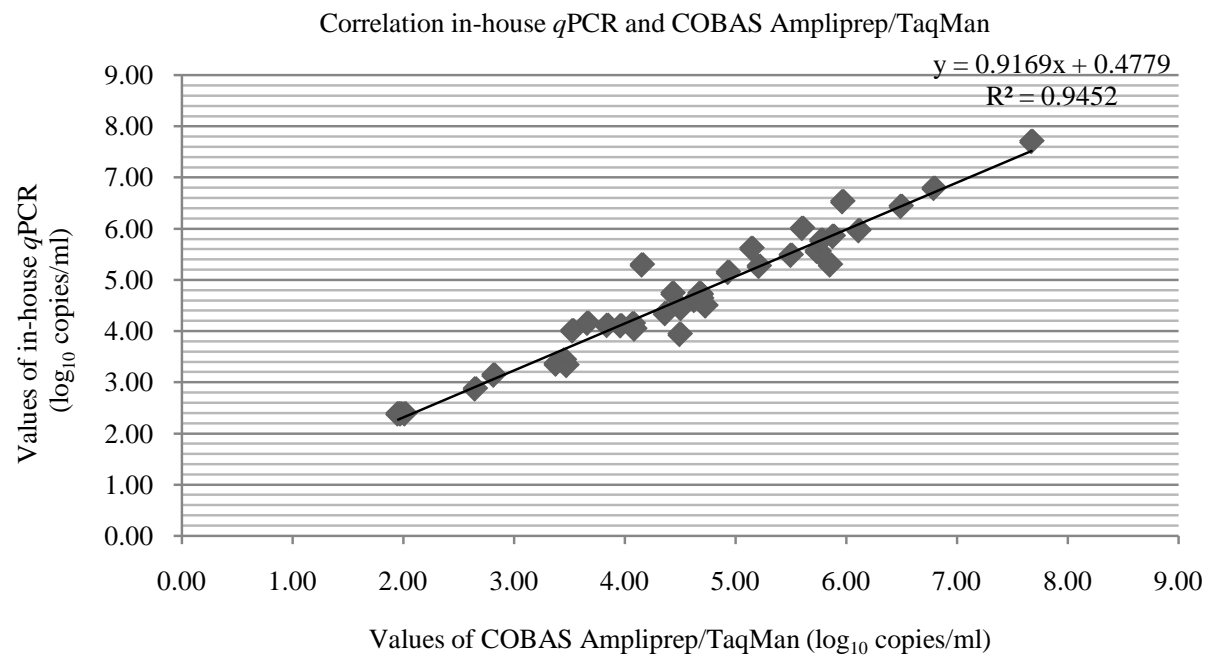

Figure 2. The correlation coefficient between the COBAS AmpliPrep/TaqManAssays and the in-house assays.

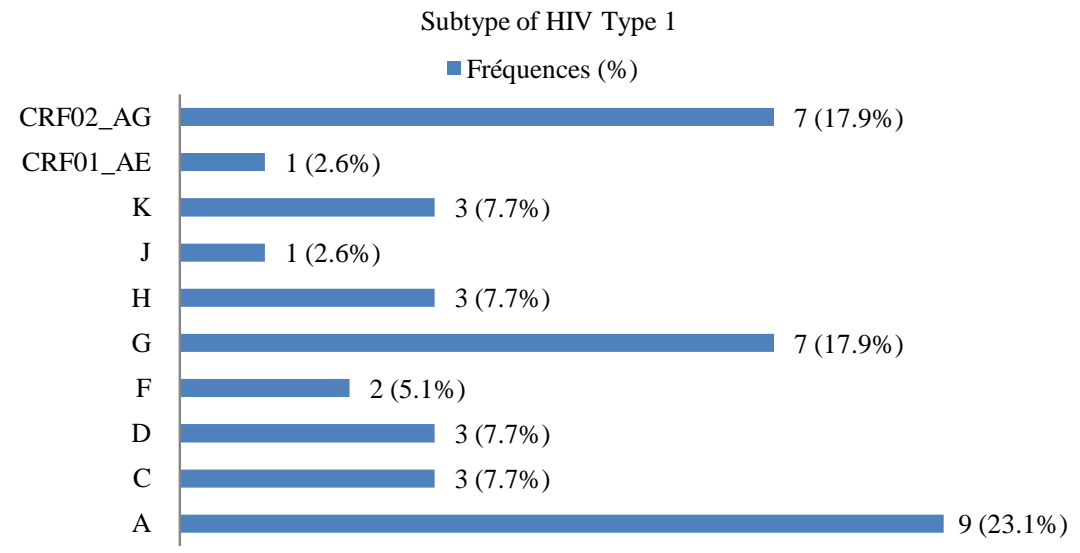

Figure 3. HIV-1 subtypes among the 39 samples. 
The results of this study demonstrate that both techniques give similar results for the determination of the VL for the non-B strains of HIV-1 after quantification of the viral RNA. The "in-house" assay targets a portion of the region of the LTR while the COBAS system simultaneously targets a portion of the gag region of the LTR. The results of this study confirm what has been previously published on these techniques with subtype B [5]-[9]. Over $89 \%$ of VL determined using the COBAS are identical to the results determined by the in-house assay. The coefficient $\left(\mathrm{R}^{2}\right)$ found for the correlation (Spearman Correlation) is strong, it is of 0.9452 . These results are consistent with those found in previous studies with subtype B [5] [7] [8]. This support the use of this "in-house" assay in resource limited settings.

Only 4 samples had discordant VL with the 2 techniques used. Indeed, two samples of subtype K $(-1.13)$ and C $(-0.56)$ were overestimated by the COBAS AmpliPrep/TaqMan and two others, subtype G (0.57) and A (0.57), were overestimated by the in-house assay. The 4 discordant samples were rerun and the same results were obtained by both techniques. These differences in VLs are not correlated with variants type of HIV-1. They can be caused by operational errors or technical errors. It's hard to blame the different variants for discordant VL. Studies with this in-house assay did not refer to the genetic diversity of HIV. Hence the need to conduct another study with a larger sample based on genetic diversity.

Of the 39 samples, the subtype A (23.1\%) is dominant, followed by G (17.9\%), CRF02_AG (17.9\%), C (7.7\%), D (7.7\%), H (7.7\%), K (7.7\%), F (5.1\%), CRF01_AE (2.6\%) and J (2.6\%). These results are consistent with published data on the various African variants [16] [17]. In the Democratic Republic of Congo (DRC), the strains most frequently reported until 2012 are A (34.3\%), G (17.3\%), D (11.2\%) [18]. In 2014, it was reported a strong presence of recombinant forms CRF02_AG (11.1\%) in Kinshasa [13]. In Chad, J strains (30.2\%), G (16.3\%), A (9.30\%) and recombinant forms CRF02-AG (30.2\%) are dominant among People Living with HIV (PLHIV) [12].

The COBAS AmpliPrep/TaqMan HIV-1 Version 2.0 is a fully closed automated system. This automated system uses only the appropriate kits for machine and requires limited technical expertise. The technical staff is reduced with the use of this system, which reduces technical errors caused by mishandling. For cons, the purchase price for the kits is the major problem because countries with limited resources have reduced funding committed to the fight against HIV/AIDS [19].

The in-house assay used in this study was developed as a less expensive alternative for the quantification of viral RNA for countries with limited resources [7] [8]. It requires suitable premises for the various steps of handling, and competent and well trained personnel for the various handling. Nevertheless, it has advantages for laboratories in these countries. Out of its reliability and repeatability, it turns out a fairly simple technology. The reagents are cheaper and can be purchased separately based on the best offer on the market.

The Laboratories of Molecular Biology, of the Faculty of Medicine, at the University of Kinshasa (UNIKIN) have the right equipment to implement this "in-house" assay for the determination of VL in patients with HIV infection in Kinshasa. This technique is currently used for research in the Laboratory.

\section{Conclusion}

Our study demonstrates that there is no significant difference between the results of Viral Loads (VL) determined by the COBAS AmpliPrep/TaqMan technology and the in-house technique used. It can be recommended for countries with limited resources in terms of its feasibility, low technical needs and low cost. However, each requires a deep assessment before being implemented by qualified personnel. Further research is needed to determine the involvement of different subtypes in determining the VL.

\section{Conflict of Interest}

The authors declare that there is no conflict of interest.

\section{Authors' Contribution}

EK, AC and DV conceived the study. MPH, RK, PDM and GM participated in the study design. EK coordinated data collection. EK, AC and RB performed laboratory work, data analysis and interpretation of results. FS and RB participated in laboratory analysis. DV coordinated laboratory analysis. FS, RB and DV participated in interpretation of results. EK drafted the manuscript. All authors contributed to the writing, read and approved the final manuscript. 


\section{References}

[1] Department of Health and Human Services (DHHS) (2011) Guidelines for the Use of Antiretroviral Agents in HIVInfected Adults and Adolescents. US Government Printing Office, Washington DC, 174.

[2] World Health Organization (WHO) (2006) Towards Universal Access by 2010. How WHO Is Working with Countries to Scale-Up HIV Prevention, Treatment, Care and Support. World Health Organization, Geneva. www.who.int/hiv/universalaccess2010

[3] World Health Organization (WHO) (2010) Antiretroviral Therapy for HIV Infection in Adults and Adolescents: Recommendations for a Public Health Approach (2010 Revision). World Health Organization, Geneva. www.who.int/publications/2010/9789241599764_eng.pdf

[4] Thompson, M.A., Aberg, J.A., Cahn, P., Montaner, J.S., Rizzardini, G., Telenti, A., Gatell, J.M., Gunthard, H.F., Hammer, S.M., Hirsch, M.S., Jacobsen, D.M., Reiss, P., Richman, D.D., Volberding, P.A., Yeni, P. and Schooley, R.T. (2010) Antiretroviral Treatment of Adult HIV Infection: 2010 Recommendations of the International AIDS Society-USA Panel. JAMA, 304, 321-333. http://dx.doi.org/10.1001/jama.2010.1004

[5] Steegen, K., Luchters, S.S., De Cabooter, N., Reynaerts, J., Mandaliya, K., Plum, J., Jaoko, W., Verhofstede, C. and Temmerman, M. (2007) Evaluation of Two Commercially Available Alternatives for HIV-1 Viral Load Testing in Resource-Limited Setting. Journal of Virological Methods, 146, 178-187. http://dx.doi.org/10.1016/j.jviromet.2007.06.019

[6] Rouet, F. and Rouzioux, C. (2007) The Measurement of HIV-1 Viral Load in Resource-Limited Setting: How and Where? Clinical Laboratory, 53, 135-148.

[7] Rouet, F., Chaix, M.L., Nerrienet, E., Ngo-Giang-Huong, N., Plantier, J.C., Burgard, M., Peeters, M., Damond, F., Koumavi, E.D., Msellati, P., Ferradini, L., Rukobo, S., Maréchal, V., Schvachsa, N., Wakrim, L., Rafalimanana, C., Rakotoambibiba, B., Viard, J.P., Seigneurin, J.M., Rouzioux, C. and for the Agence Nationale de Recherchessur le SIDA AC11/AC12 Working Groups (2007) Impact of HIV-1 Genetic Diversity on Plasma HIV-1 RNA Quantification. Journal of Acquired Immune Deficiency Syndromes, 45, 380-388. http://dx.doi.org/10.1097/QAI.0b013e3180640cf5

[8] Rouet, F., Foulongne, V., Viljoen, J., Steegen, K., Becquart, P., Valéa, D., Danaviah, S., Segondy, M., Verhofstede, C., Van de Perre, P. and for the WHO/ANRS 1289 Kesho Bora Study Group (2010) Comparison of the Generic HIV Viral Load $^{\circledR}$ Assay with Amplicor ${ }^{\mathrm{TM}}$ HIV-1 Monitoring v1.5 and Nuclisens HIV-1 EasyQ ${ }^{\circledR}$ v1.2 Techniques for Plasma HIV-1 RNA Quantification of Non-B Subtypes: The Kesho Bora Preparatory Study. Journal of Virological Methods, 163, 253-257. http://dx.doi.org/10.1016/j.jviromet.2009.10.005

[9] Drosten, C., Panning, M., Drexler, J.F., Hänsel, F., Pedrosoc, C., Yeats, J., de Souza Luna, L.K., Samuel, M., Liedigk, B., Lippert, U., Stürmer, M., Doerr, H.W., Brites, C. and Preiser, W. (2006) Ultrasensitive Monitoring of HIV-1 Viral Load by a Low-Cost Real-Time Reverse Transcription-PCR Assay with Internal Control for 5' Long Terminal Repeat Domain. Clinical Chemistry, 52, 1258-1266. http://dx.doi.org/10.1373/clinchem.2006.066498

[10] QIAGEN (2010) QIAamp ${ }^{\circledR}$ RNA Mini and Blood Mini Handbook. 3rd Edition, 27-29.

[11] Steegen, K., Demecheleer, E., De Cabooter, N., Nges, D., Temmerman, M., Ndumbe, P., Mandaliya, K., Plum, J. and Verhofstede, C. (2006) A Sensitive In-House RT-PCR Genotyping System for Combined Detection of Plasma HIV-1 and Assessment of Drug Resistance. Journal of Virological Methods, 133, 137-145. http://dx.doi.org/10.1016/j.jviromet.2005.11.004

[12] Adawaye, C., Kamangu, N.E., Moussa, A.M., Tchombou, H.Z.B., Vaira, D. and Moutshen, M. (2015) Prévalence de la résistance acquise et diversité génétique des souches du VIH-1 circulant à Ndjamena au Tchad. In Press.

[13] Kamangu, N.E., Adawaye, C., Susin, F., Boreux, R., Kalala, L.R., Mvumbi, L.G., De Mol, P., Vaira, D. and Hayette, M.P. (2015) Genetic Diversity and Antiretroviral Drug Resistance among Drug-Naïve HIV Type 1 Infected Patients Attending Clinics in Kinshasa, Democratic Republic of Congo. In Press.

[14] Tang, M.W., Liu, T.F. and Shafer, R.W. (2012) The HIVdb System for HIV-1 Genotypic Resistance Interpretation. Intervirology, 55, 98-101.

[15] Viard, J.P. (2008) Surveillance biologique du patient sous traitement antiretroviral. Revue Francophone des Laboratoires, 399, 22-24.

[16] Thomson, M.M. and Najera, R. (2005) Molecular Epidemiology of HIV-1 Variants in the Global AIDS Pandemic: An Update. AIDS Reviews, 7, 210-224.

[17] Shao, Y. and Williamson, C. (2012) The HIV-1 Epidemic: Low- to Middle-Income Countries. Cold Spring Harbor Perspectives in Medicine, 2, a007187.

[18] Kamangu, N.E., Kabututu, Z., Mvumbi, L.G., Kalala, L.R. and Mesia, K.G. (2013) Genetic Diversity of Human Immunodeficiency Virus Type 1 in the Democratic Republic of Congo. International Journal of Collaborative Research on Internal Medicine \& Public Health (IJCRIMPH), 5, 295-309. 
[19] Kamangu, N.E., Kalala, N.H. and Mesia, K.G. (2012) Profile of Antiretroviral Treatment Centers in Kinshasa, Democratic Republic of Congo [Poster 388]. Proceedings of the 1st International African Society of Laboratory Medicine (ASLM) Conference, Cape Town, 1-7 December 2012, 377. 